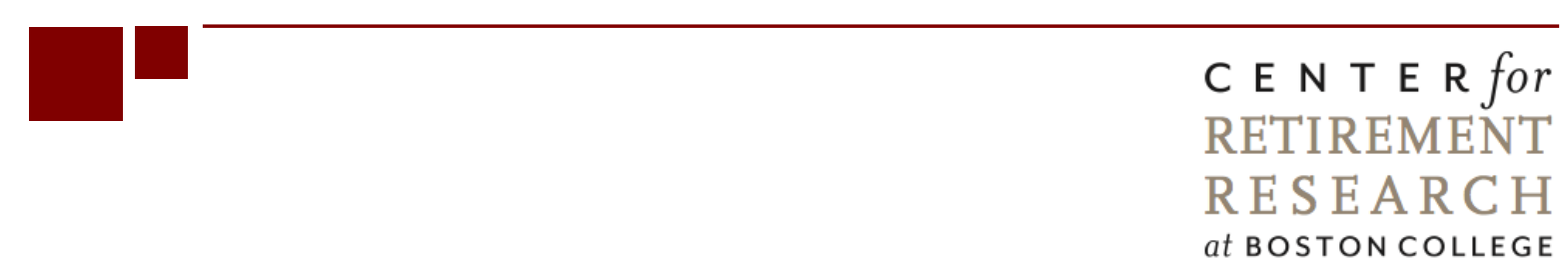

\title{
CAN LONG-TERM CARE INSURANCE PARTNERSHIP PROGRAMS INCREASE COVERAGE AND REDUCE MEDICAID COSTS?
}

\author{
Wei Sun and Anthony Webb
}

CRR WP 2013-8

Released: March 2013
Center for Retirement Research at Boston College
Hovey House
140 Commonwealth Avenue
Chestnut Hill, MA 02467
Tel: 617-552-1762
http://crr.bc.edu

Anthony Webb is a senior research economist at the Center for Retirement Research at Boston College. Wei Sun is an The research reported herein was pursuant to a grant from the National Institutes of Health $(\mathrm{NIH})$. The findings and conclusions expressed are solely those of the authors and do not represent the views of the NIH, Renmin University of China, or Boston College.

(C) 2013, Wei Sun and Anthony Webb. All rights reserved. Short sections of text, not to exceed two paragraphs, may be quoted without explicit permission provided that full credit, including (C) notice, is given to the source. 


\title{
About the Center for Retirement Research
}

The Center for Retirement Research at Boston College, part of a consortium that includes parallel centers at the University of Michigan and the National Bureau of Economic Research, was established in 1998 through a grant from the Social Security Administration. The Center's mission is to produce first-class research and forge a strong link between the academic community and decision-makers in the public and private sectors around an issue of critical importance to the nation's future. To achieve this mission, the Center sponsors a wide variety of research projects, transmits new findings to a broad audience, trains new scholars, and broadens access to valuable data sources.

\author{
Center for Retirement Research at Boston College \\ Hovey House \\ 140 Commonwealth Avenue \\ Chestnut Hill, MA 02467 \\ phone: 617-552-1762 fax: 617-552-0191 \\ e-mail: crr@bc.edu \\ crr.bc.edu
}

Affiliated Institutions:

The Brookings Institution

Massachusetts Institute of Technology

Syracuse University

Urban Institute 


\begin{abstract}
Although long-term care is a substantial financial risk for retired households, only about 10 percent purchase insurance, with many of the remainder relying on Medicaid. Faced with rising Medicaid expenditures on long-term care, states have attempted to encourage the purchase of private long-term care insurance through partnership programs that exempt purchasers of qualifying policies from the Medicaid asset test. Using numerical optimization techniques, and assuming plausible preference parameters, we show that the programs will only increase insurance coverage among single males by 5 percent and single females by 4 percent. Most of the program benefits will go to those who would have purchased non-partnership long-term care insurance anyway. Thus, the cost of the subsidy will exceed the savings in Medicaid costs.
\end{abstract}




\section{Introduction}

The cost of nursing home care represents a significant financial risk for elderly Americans. Brown and Finkelstein (2008) estimate that 27 percent of men and 44 percent of women will enter nursing home at some point after age 65. Among those who do, 33 percent of men and 42 percent of women will spend more than a year in a nursing home. MetLife Mature Market Institute (2012) reports that the average cost of a semi-private room in a nursing home was \$214 per day, or \$78,110 annually, in 2011. Despite this very considerable financial risk, few Americans purchase long-term care insurance. Many households lack the resources to pay out of pocket and turn to Medicaid, the health insurance program for the indigent. The National Health Policy Forum (2013) reports that in 2011 Medicaid paid for 62.3 percent of total longterm care expenditure of $\$ 210.9$ billion. Concerned at spiraling Medicaid costs, a number of states have introduced long-term care insurance partnership programs. Their goal is to reduce the financial pressure on Medicaid by encouraging individuals to purchase private long-term care insurance.

Using numerical optimization techniques, this paper investigates the impact of the above partnership programs on long-term care insurance coverage and Medicaid costs. As in Brown and Finkelstein (2008), the analysis focuses on optimal behavior of single individuals, given assumed preference parameters. We show that, under our assumption of optimizing behavior, these programs will increase coverage rates by only 4 to 5 percentage points. A typical induced male purchaser is someone around the $70^{\text {th }}$ wealth percentile. Prior to purchasing insurance, Medicaid would pay about 36 percent of his long-term care costs. With partnership coverage, the Medicaid share would halve to 18 percent. But this saving is more than offset by an increase in Medicaid expenditure on those who currently purchase non-partnership policies but who will switch to more advantageous partnership policies. For example, the Medicaid share of the long-

term care costs of a male at the $80^{\text {th }}$ percentile of the wealth distribution would increase from zero to 3 percent before the introduction of the partnership program to 14 percent afterwards, when he switches from a non-partnership to a partnership policy. We estimate that each onedollar saving in Medicaid costs requires partnership subsidies of \$1.68 to \$2.30 for single males and $\$ 4.10$ to $\$ 5.38$ for single females.

The remainder of the paper is as follows. Section 1 outlines the financing of long-term care in the United States and describes the history and current rules of the long-term care 
insurance partnership programs. Section 2 reviews previous research. Section 3 presents the intertemporal optimization model. Section 4 presents our results, and section 5 concludes.

\section{Financing Long-term Care in the United States}

Social insurance programs cover the cost of long-term care in only the following circumstances:

Nursing home care. Medicare, the public health insurance program for the elderly, covers nursing care for no more than 100 days, and only if this care is in a skilled nursing facility and follows a hospital stay of more than three consecutive days. Medicaid pays for the nursing home care of the indigent, but is subject to a stringent means test. Importantly, Medicaid has secondary payer status, providing benefits only to those who are uninsured and who cannot afford care. Single individuals claiming Medicaid are typically permitted to retain assets of $\$ 2,000$ and an income of $\$ 30$ a month, contributing any excess toward the cost of their care. ${ }^{1}$

Home health care. Medicare provides partial coverage for home health care. Medicare will pay for part-time or intermittent skilled nursing care or home health aide care for qualifying individuals. $^{2}$ It will not pay for 24-hour daily home care or assistance with activities of daily living (ADL), if those are the only types of care that are required. Medicaid will provide other types of care, again subject to an asset and income means test. In 2011, the asset test is $\$ 2,000$, as for nursing home care, and the income test is $\$ 704$ a month.

Although the cost of long-term care exceeds the financial resources of most households, Brown and Finkelstein (2007) report that only about 10 percent of individuals over age 60 were covered by private long-term care insurance in the year 2000 , with coverage being strongly positively

\footnotetext{
${ }^{1}$ The income and assets of married couples are subject to less restrictive spousal protection rules designed to prevent the impoverishment of the community spouse. Married couples must also consider the impact of long-term care costs on the consumption of the surviving spouse. So our estimates of the cost of the partnership program may not apply to married couples.

${ }^{2}$ A qualifying individual must satisfy the four following conditions: 1) he must be home bound, 2) his doctor must decide that medical care is required at home and make a care plan, 3) he must need intermittent skilled nursing care, and 4) the home health agency providing the care must be Medicare approved.
} 
correlated with income. ${ }^{3}$ Policies provide a daily maximum level or increasing benefit for either an unlimited or specified duration, so purchasers are exposed to the risk of care costs increasing more rapidly than expected. Policies are guaranteed renewable, but insurers can and do apply to their state insurance regulators for permission to increase premiums, so that purchasers are exposed to the risk of sudden and sometimes large premium increases. Premiums do not differ by gender, even though women are at much greater risk than men of requiring care. In consequence, premium loads are much higher for men than for women. Brown and Finkelstein (2007) estimate that loads average 50 percent for men and minus 6 percent for women. ${ }^{4}$ Even so, coverage rates for men and women are similar. ${ }^{5}$

Concerned at rising Medicaid costs, states have both subsidized the purchase of longterm care insurance by giving premiums favorable treatment under the state income tax code and have also introduced so-called long-term care insurance partnership programs, the focus of this paper. ${ }^{6}$ Participants in these programs purchase long-term care insurance policies with benefits payable for a limited duration, typically three years. Once policy benefits are exhausted, participants claim Medicaid, but are subject to less stringent asset protection rules. The programs exempt all the assets of purchasers of "total asset protection” policies, although they are still subject to the Medicaid income test. The assets of purchasers of "dollar-for-dollar" policies are protected up to the amount of the private insurance benefit paid. When policies are purchased under a hybrid program, the type of protection depends on the initial amount of coverage purchased.

The programs began in 1987 as a demonstration project funded through the Robert Wood Johnson Foundation. ${ }^{7}$ Four states participated: California, Connecticut, Indiana, and New York. California and Connecticut have a dollar-for-dollar model. New York offers total asset protection, while Indiana operates a hybrid model. Expansion of the program to other states was

\footnotetext{
${ }^{3}$ Brown and Finkelstein (2009) review demand and supply side factors that may contribute to low levels of insurance coverage.

${ }^{4}$ Loads are defined as $\left(1-\frac{\text { EPDVbenefits }}{\text { EPDVpremiums }}\right)$. Estimates of the loads depend on the assumptions made about discount and lapse rates, as discussed in Brown and Finkelstein (2007).

${ }^{5}$ Most individuals approaching retirement are married, and one plausible explanation is that the decision to initiate coverage is taken jointly by the couple. Coverage rates among single women are somewhat higher than among single women.

${ }^{6}$ Some states allow a deduction. Others allow a non-refundable tax credit.

${ }^{7}$ See Rothstein (2007) for a fuller discussion.
} 
halted by legislation that required states to recover the cost of long-term care from the estates of Medicaid beneficiaries. This obstacle was addressed by the Deficit Reduction Act (DRA) of 2005, and the partnership program has now been made available to all states, subject to compliance with legislative guidelines. Importantly, the DRA requires states to offer inflation protection, but allows the extent of that protection to vary with age.

\section{Previous Research}

Previous research into the impact of Medicaid and tax subsidies on the long-term care insurance purchase decision falls into two categories, calculations of optimal behavior, given assumed preference parameters, and empirical studies. Pauly (1990) provided a theoretical explanation of rational non-purchase of long-term care insurance in the presence of Medicaid. He showed that even though it provided incomplete insurance, it could crowd out private insurance even among individuals at relatively low risk of spending down to Medicaid.

Brown and Finkelstein (2008) constructed an intertemporal optimization model of the long-term care insurance purchase decision faced by single individuals. They showed that Medicaid crowd-out is sufficient to explain a large part of the lack of demand. For plausible preference parameters, they found only the very wealthy would be willing to pay for private long-term care insurance because much of the benefit accrues to the government in the form of lower Medicaid expenditure rather than to the individual in the form of higher consumption. ${ }^{8}$ Brown and Finkelstein (2007) present evidence of supply side market failures that render longterm care insurance policies even more unattractive to would-be purchasers. ${ }^{9}$ So their theoretical model may, if anything, overstate willingness to pay for long-term care insurance.

Empirical studies include Courtemanche and He (2009), who analyzed Health and Retirement Study (HRS) data. They concluded that although the federal tax subsidies in the Health Insurance Portability and Accountability Act of 1966 (HIPAA) increased the take-up of

\footnotetext{
${ }^{8}$ The working paper version of Brown and Finkelstein (2008), Brown and Finkelstein (2004) reports the impact of the partnership program for a single illustrative case. They find that eliminating the Medicaid asset test would increase the willingness-to-pay of a male at the $50^{\text {th }}$ percentile of the wealth distribution by a mere $\$ 3,400$.

${ }^{9}$ Although insurance companies guarantee the right of the insured to renew coverage, the insurer can apply to the state insurance regulator for permission to increase rates on a block of business. In recent years, insurance companies have increased premiums, partly in response to declines in long-term interest rates. An individual who purchases a long-term care insurance policy therefore exchanges an uncertain obligation to pay for long-term care with an obligation to pay insurance premiums of an uncertain amount over an uncertain duration, further decreasing the attractiveness of insurance.
} 
long-term care insurance by 25 percent from a low base, implying a high level of elasticity to the after-tax price of insurance, the subsidy would result in a net revenue loss to the government. Also using HRS data, Shah Goda (2011) studied the impact of state-level income tax subsidies on the demand for long-term care insurance. She estimated that the average tax subsidy raised coverage rates by 30 percent, but that the increase was concentrated among asset-rich individuals at relatively low risk of becoming Medicaid eligible so that each dollar of subsidy yielded only 84 cents in Medicaid savings. Brown, Coe, and Finkelstein (2007) show that long-term care insurance coverage is higher in states with less generous Medicaid spousal protection rules, suggesting that asset protection influences the long-term care insurance purchase decision. Using HRS data, Chan and Sun (2011) estimate a structural model of the long-term care insurance purchase decision by single individuals. They conclude that individuals have only a modest preference for higher quality non-Medicaid care. They find that premium subsidies would substantially increase insurance coverage, but that the reduction in Medicaid expenditure would be insufficient to offset the subsidy cost, findings that are consistent with those of the reduced form models discussed above. Finally, using HRS data, Lin and Prince (2012) exploit plausibly exogenous variation in the dates states introduced partnership programs and conclude that any effect on coverage was both small and concentrated among wealthy individuals at relatively low risk of becoming dependent on Medicaid.

The U.S. Government Accountability Office (GAO, 2005) reported that more than half of purchasers in California, Connecticut, and Indiana had assets in excess of \$350,000 and more than half had monthly incomes in excess of $\$ 5,000$. These averages indicate that the programs are attracting more well-to-do households that are at relatively low risk of becoming Medicaid eligible. The GAO study did not investigate the impact on coverage, and in particular whether they had resulted in an increase in coverage relative to other states that did not operate a program.

The above evidence notwithstanding, appears to be a widespread belief that the partnership programs reduce Medicaid expenditure. America’s Health Insurance Plans (2007) calculate that state-level partnership programs could potentially reduce Medicaid costs by $\$ 6$ billion a year by 2050. But their calculations are based on arbitrary assumptions about the impact of the partnership program on coverage rates and failed to model the likely relationship between coverage and the risk of becoming Medicaid eligible. The National Conference of State 
Legislatures (2013) reports that that Connecticut officials estimated that the partnership program had saved the state $\$ 3.75$ million since inception, an estimate based on similarly arbitrary assumptions.

\section{Model}

Using numerical optimization techniques, this paper evaluates the impact of dollar-fordollar and total asset protection partnership programs on the amounts single individuals would hypothetically be willing to pay for long-term care insurance and the corresponding impact of Medicaid expenditure, given assumed preference parameters.

Our model follows that of Brown and Finkelstein (2008). In each month, the individual can be in one of five states, at home receiving no care, at home receiving home health care, living in an assisted living facility, living in a nursing home, or dead. Transition probabilities vary with age and gender and are based on Robinson (2002). We calculate insurance premiums by applying Brown and Finkelstein (2007) estimates of market loads of 50 percent for men and 6 percent for women to actuarially fair premiums calculated using the Robinson (2002) model. ${ }^{10}$

The individual derives utility from consumption, $C_{s, t}$. In a nursing home or assisted living facility, the individual also derives utility from food and shelter $F_{s, t}$ that would otherwise need to be paid out-of-pocket. The consumer's problem is, therefore, to maximize:

$$
\sum_{t=65}^{T=105} \sum_{s=1}^{s=5} \frac{Q_{s, t}}{(1+\rho)} U\left(C_{s, t}+F_{s, t}\right)
$$

where $Q_{s, t}$ is the probability of being in state $\boldsymbol{s}$ at time $t$, and $\boldsymbol{\rho}$ is a rate of time preference. Individuals face the following budget constraint when not eligible for Medicaid:

$$
W_{t+1}=\left(W_{t}+A_{t}+\min \left[B_{s, t}, X_{s, t}\right]-P_{s, t}-X_{s, t}-C_{s, t}\right)(1+r)
$$

\footnotetext{
${ }^{10}$ The Robinson (2002) model is based on data from the 1982 and 1984 National Long-Term Care Survey. Although there is evidence that the incidence of activity of daily living (ADL) limitations, a key determinant of long-term care utilization, has declined over the last 30 years, updating the model is beyond the scope of this paper. Expense loads depend on premiums, claim rates, and the interest rate used to discount premiums and claims. Although long-term care insurance premiums have increased substantially in recent years, policies have an extremely long duration, and much of the increase likely reflects declines in nominal interest rates.
} 
where $W$ is wealth, $A$ is annuitized income, $B$ and $P$ are long-term insurance policy benefits and premiums, $\boldsymbol{X}$ is the cost of long-term care, and $\boldsymbol{r}$ is the rate of interest. Policy benefits are capped at the actual level of long-term care costs incurred. Premiums are only paid when living at home and not receiving care. The uninsured receive zero policy benefits and pay zero premiums. There is the usual no-borrowing constraint.

If the individual is eligible for Medicaid, Medicaid pays an amount equal to:

$$
X_{s, t}-\left(A_{t}+B_{s, t}-\underline{C}_{s}\right)-\max \left(W_{t}-\underline{W, 0}\right)
$$

the cost of long-term care minus the amount by which annuitized income exceeds $\underline{\boldsymbol{C}}$ a consumption floor, which varies with care status , minus long-term care insurance policy benefits, minus the lesser of zero and the amount by which wealth exceeds $\underline{W}$, the wealth floor.

If the individual purchases a partnership policy, the Medicaid asset test is relaxed. After the expiry of the policy benefit period, Medicaid pays:

$$
X_{s, t}-\left(A_{t}-\underline{C}_{s}\right)-\max \left(W_{t}-\underline{\underline{W}}, 0\right)
$$

the cost of care, minus the amount by which the individual's income exceeds the Medicaid income floor. In the case of a dollar-for-dollar policy, $\underline{W}$, the revised wealth floor, equals the total benefits paid under the policy, plus the $\$ 2,000$ disregard. In the case of a total asset protection policy, it is set to infinity.

The remaining parameter values of our model are as follows. The terminal age $\mathrm{T}$ is set at 105. The real interest rate and the rate of time preference are both 3 percent. ${ }^{11}$ General inflation is 2.5 percent a year, and real medical cost inflation is 1.5 percent a year. The 2011 costs of a semi-private room in a nursing home, a room in an assisted living facility, and home health care are assumed to be $\$ 78,110$ and $\$ 41,724$ a year, and $\$ 21$ an hour, respectively, as reported by

\footnotetext{
${ }^{11}$ The current long-run real risk-free interest rate, as measured by Treasury Inflation Protected Securities, is close to zero. We chose to retain an assumption of three percent as this is standard in the decumulation literature and facilitates comparison with Brown and Finkelstein (2008).
} 
MetLife Mature Market Institute (2012). ${ }^{12}$ The Medicaid income and asset tests are $\$ 30$ a month and $\$ 2,000$, respectively. The consumption value of food and accommodation in a nursing home or assisted living facility is assumed to be \$674, the 2011 Supplementary Security Income (SSI) benefit amount. $^{13}$ The consumption floor is set at \$30 if in a nursing home, \$704 if receiving home health care. Wealth deciles are based on Brown and Finkelstein (2008), uprated by CPI inflation from 2000 to 2011.

\section{Results}

We calculate willingness to pay for the most commonly purchased non-partnership policy type, providing a daily benefit of \$158 in 2011 dollars for a duration of three years, with 5 percent inflation protection (America's Health Insurance Plans 2012). To explore the impact of tail risk, we then calculate willingness to pay for a policy with the above daily benefit, but with an unlimited duration of coverage. To explore the impact of benefit amount, we also calculate willingness to pay for three-year and unlimited duration policies with a larger daily benefit of \$241, the minimum daily benefit required for total asset protection in 2011. Finally, we investigate the impact of the partnership program by calculating willingness to pay for dollar-fordollar partnership policies with daily benefit amounts of \$158 and \$241, and a total asset protection partnership policy with a daily benefit amount of \$241. In all cases, we assume market loads.

To summarize, the policy types studied are as follows:

- $\quad$ Policy 1: Typical non-partnership policy, three-year coverage, \$158 daily benefit.

- Policy 2: Non-partnership policy, lifetime coverage, \$158 daily benefit.

- Policy 3: Non-partnership policy, three-year coverage, \$241 daily benefit.

- Policy 4: Non-partnership policy, lifetime coverage, \$241 daily benefit.

- Policy 5: Partnership policy, three-year coverage, with dollar-for-dollar protection thereafter, \$158 daily benefit.

- Policy 6: Partnership policy, three-year coverage, with dollar-for-dollar protection thereafter, \$241 daily benefit.

\footnotetext{
${ }^{12}$ In the interests of computational feasibility, we assume, when analyzing dollar-for-dollar policies that care costs equal or exceed the daily policy benefit. This enables us to model the policy as protecting some dollar amount of assets - which is the way the policies are usually marketed. MetLife Mature Market Institute (2012) report that the costs in New York State are somewhat higher at \$125,560, \$46,404, and \$22, respectively. MetLife does not report the cost of skilled nursing care in 2011, and we assume that it increased at the same rate as the cost of home health care.

${ }^{13}$ Some states pay a somewhat higher SSI benefit. The $\$ 674$, plus the $\$ 30$ personal needs allowance equals the $\$ 704$ consumption floor.
} 
- Policy 7: Partnership policy, three-year coverage, with total asset protection thereafter, \$241 daily benefit.

In our base case, we assume the rate of interest and the rate of time preference both equal 3 percent. We consider an alternative in which the rate of interest is 1 percent, reflecting the current low interest rate environment, but retain the assumption of a 3 percent rate of time preference.

Figures $1 \mathrm{~A}$ and $1 \mathrm{~B}$ show willingness to pay for the Policies 1, 4, 5 and 7 for males and females respectively, assuming a 3 percent rate of interest. We do not report willingness-to-pay when it is worse than losing all financial wealth.

Men. Men at the $71^{\text {st }}$ wealth percentile and above have a positive willingness to pay for the typical policy, one that provides a $\$ 158$ daily benefit for a three-year duration. Their willingness to pay for a three-year duration policy with a $\$ 241$ daily benefit is almost identical and is not shown on the figure. Men at the $72^{\text {nd }}$ wealth percentile and above have a positive willingness to pay for an unlimited duration $\$ 241$ daily benefit policy. Their willingness to pay for an unlimited duration $\$ 158$ daily benefit policy is almost identical and is not shown on the figure.

The wealthy place a substantially higher value on an unlimited duration than on a threeyear duration policy. They value the ability to insure against the risk of catastrophic long-term care costs. This finding is in contrast with observed behavior, with many purchasers opting for a limited duration of coverage. But men at low wealth percentiles prefer the less expensive threeyear duration policy to the more expensive unlimited duration policy, while still preferring to purchase neither,.

Men at all wealth percentiles prefer the $\$ 158$ daily benefit partnership policy to the corresponding three-year duration policy. The partnership policy provides superior benefits at the same premium. But the additional willingness to pay is strongly related to wealth. Those at low wealth percentiles place almost no value on the additional insurance. Those in the top wealth percentiles, who stand to lose a lot in the unlikely event of requiring more than three years of care, place a high value on the additional insurance. At all wealth percentiles, willingness to pay for the three partnership policies is very similar. The very wealthy have a slight preference for the $\$ 241$ daily benefit total protection policy. 
The very wealthy also prefer the unlimited duration non-partnership policy to a partnership policy with the same level of benefits. This is because the unlimited duration policy protects both assets and income, whereas the partnership policy protects only assets, and in the case of the $\$ 158$ daily benefit policy, only protects assets up to the amount of policy benefits. An important implication of this finding is that the very wealthy may continue to purchase nonpartnership policies rather than switching to partnership policies, reducing the deadweight cost of the program. ${ }^{14}$

Women. The patterns among women exhibit many similarities with men but also some differences. Women have a higher willingness to pay for all policies, reflecting unisex pricing and a higher risk of requiring care. Women have a positive willingness to pay for the three-year duration $\$ 158$ daily benefit and unlimited duration $\$ 241$ daily benefit policies at the $60^{\text {th }}$ and $63^{\text {rd }}$ percentile, respectively, compared with the $71^{\text {st }}$ and $72^{\text {nd }}$ for men. At the highest wealth percentiles, women have a substantially higher willingness to pay for the total protection partnership policy than for either of the other two partnership policies. But, as in the case of men, wealthy women prefer an unlimited duration non-partnership policy to a partnership policy with the same benefit level.

In results that are not reported, we calculate willingness to pay at a 1 percent real interest rate. Individuals place a lower value on all types of long-term care insurance, reflecting their preference for higher consumption earlier in retirement at lower real rates of return.

We now calculate the impact of the partnership programs on the Medicaid share of the expected present value (EPV) of total long-term care expenditures. The eight columns of Table 1 report the Medicaid share under the assumptions of 1) no private insurance; 2) a typical nonpartnership policy with 3-year duration of coverage and \$158 daily benefit; 3) a non-partnership policy with unlimited duration of coverage and \$158 daily benefit; 4) a three year duration nonpartnership policy with $\$ 241$ daily benefit; 5) an unlimited duration non-partnership policy with \$241 daily benefit; 6) a dollar-for-dollar partnership policy with \$158 daily benefit for three years; 7) a dollar-for-dollar partnership policy with \$241 daily benefit for three years; and 8) a

\footnotetext{
${ }^{14}$ Individuals are assumed to gradually decumulate their financial assets during retirement, so that even men with high initial levels of wealth will have fallen below the dollar-for-dollar limit by the ages at which they are at significant risk of requiring care.
} 
total asset protection partnership policy with \$241 daily benefit for three years. All policies provide 5 percent inflation protection.

In the absence of private insurance, Medicaid pays 89 percent of the long-term care costs of men at the $20^{\text {th }}$ percentile, and 8 percent of the costs of those at the $90^{\text {th }}$ percentile. Medicaid pays 28 percent of the costs of men at the $20^{\text {th }}$ percentile covered by the typical non-partnership policy, decreasing to 0.3 percent at the $90^{\text {th }}$ percentile. The unlimited duration policy with a \$241 daily benefit pays 100 percent of the cost of care, and Medicaid therefore pays none of the cost of men purchasing this policy type. Medicaid pays 28 percent, 25 percent and 25 percent of the costs of $20^{\text {th }}$ percentile men covered by the three types of partnership policies studied, decreasing to 8 percent, 10 percent and 16 percent, respectively, at the $90^{\text {th }}$ percentile. At the $20^{\text {th }}$ percentile, the Medicaid share of long-term care costs of purchasers of partnership policies is almost identical to the Medicaid share of the costs of holders of non-partnership three-year policies, because low wealth households have little wealth to protect. At high wealth percentiles, Medicaid pays much larger shares of the cost of care of holders of partnership policies, reflecting the generous asset protection rules. The Medicaid share is highest for holders of total asset protection policies.

Patterns among women are similar to those among men, except that the Medicaid share of the EPV of long-term care costs is consistently higher at all ages and for all wealth percentiles. This is because women are at greater risk of requiring an extended period of long-term care.

The seven columns of Table 2 show the implicit Medicaid tax on each of the seven policies, defined as the change in the EPV of Medicaid expenditures resulting from the purchase of long-term care insurance, divided by the EPV of the gross benefits from the insurance policy. In the lower wealth deciles, non-partnership policies are subject to a very high implicit tax because, in the absence of long-term care insurance, Medicaid would cover almost all long-term care costs. The implicit tax on the partnership policy is almost identical, because these households have almost no assets to be protected. At high wealth percentiles, the partnership policies are subject to a negative implicit tax because purchase of the policy increases the EPV of Medicaid benefits. For instance, consider a female at the $90^{\text {th }}$ percentile of the wealth distribution. The EPV of her lifetime long-term care costs is $\$ 65,280$. If she does not purchase insurance, the EPV of her Medicaid claim is 10.5 percent of this amount, or $\$ 6,842$. If she purchases a total asset protection partnership policy with an EPV of benefits of \$36,896, the EPV 
of the amount Medicaid will contribute increases to $\$ 18,719$, resulting in a minus 32 percent implicit tax.

Table 3 shows the net loads on the seven insurance policies. The net load equals one minus the EPV of policy benefits minus the EPV of the Medicaid benefits foregone, plus the EPV of any increased Medicaid benefits receivable by reason of the more generous asset protection rules resulting from the purchase of the policy, divided by the EPV of premiums. Consider again a woman at the $90^{\text {th }}$ wealth percentiles, purchasing a total asset protection policy. The EPV of policy benefits is \$36,896. In the absence of insurance, the EPV of her Medicaid costs is $\$ 6,842$. But after she has purchased insurance, the EPV of her Medicaid benefits increases to $\$ 18,719$. So the overall benefit of the policy is $\$ 48,773$. The EPV of premiums is $\$ 34,873$, yielding a net load of minus 39.9 percent.

For both men and women, the partnership program has a negligible effect on net loads at low wealth levels. At high wealth levels, the effect is much greater for women than for men and is greater for the total asset protection policy that for the dollar-for-dollar policy. The greatest impact on loads is for high-wealth women purchasing total asset protection policies.

We then investigate the potential impact of the partnership program on long-term care insurance and Medicaid finances. This will depend on 1) the number of people who are induced to purchase partnership policies, 2) the number of people who switch from non-partnership to partnership policies, and 3) the impact of participation on the amounts these groups claim under Medicaid. There are an almost infinite number of combinations of policy benefits that individuals could choose. A fully optimizing model would consider all policy options for all points on the wealth distribution, a task that is computationally infeasible.

We therefore make two alternative simplifying assumptions. In the first alternative, we assume that, prior to the partnership program, individuals purchase the typical policy, one that provides a \$158 daily benefit for three years, if willingness to pay exceeds zero. After the introduction of the partnership program, individuals purchase a $\$ 158$ daily benefit dollar-fordollar policy if willingness to pay exceeds zero, with those who would have previously purchased a non-partnership policy switching to the partnership policy.

In the second alternative, we assume that, prior to the introduction of the partnership programs, individuals purchase the non-partnership policy with the highest willingness to pay among four possible policy types, subject to willingness to pay being greater than zero. After the 
introduction of the partnership programs, they purchase whichever of all seven policies has the highest willingness to pay. Some but not all of those who would have purchased a nonpartnership policy before the introduction of the program switch to a partnership policy. The first alternative takes account of the observed preferences of existing purchasers, whereas the second alternative assumes fully optimizing behavior, given the policy types included in our analysis and our assumed preference parameters.

Under the first alternative, in the absence of the partnership program, 30 percent of men and 41 percent of women purchase insurance and the remainder - 70 and 59 percent - choose to forgo insurance. Following the introduction of the partnership program, 5 percent of men and 4 percent of women are induced to initiate coverage. These are relatively high-wealth individuals. Prior to initiating coverage, their average EPVs of Medicaid benefits were \$10,194 and \$42,967 respectively for men and women. After initiating coverage, their average EPVs of Medicaid benefits decline to $\$ 4,787$ and $\$ 23,322$, respectively. But the 30 percent and 41 percent who already have insurance will switch from non-partnership to partnership policies. Their average EPV of Medicaid benefits will increase from $\$ 866$ and $\$ 7,114$ to $\$ 2,679$ and $\$ 14,665$, respectively. Averaged over all three groups, a one dollar saving in Medicaid costs by those who are induced to purchase insurance requires $\$ 2.30$ and $\$ 4.10$ increases, for men and women respectively, in Medicaid benefits paid to those who would have purchased a non-partnership policy anyway. Those who remain uninsured have no impact on Medicaid spending.

We now consider the second alternative. Prior to the introduction of the partnership program, a total of 30 percent of men and 41 percent of women purchase various types of nonpartnership policy. ${ }^{15}$ The remainder - 70 and 59 percent - choose to forgo insurance. Following the introduction of the partnership program, 5 percent of men and 4 percent of women are induced to purchase a partnership policy. Induced male purchasers prefer the \$158 dollar-fordollar policy and induced female purchasers prefer the $\$ 241$ total asset protection policy, reflecting differences in market loads and long-term care utilization. These are again relatively high-wealth individuals. Prior to initiating coverage, their average EPVs of Medicaid benefits were $\$ 10,194$ and $\$ 42,967$, respectively for men and women. After initiating coverage, their average EPVs of Medicaid benefits decline to \$4,787 and \$23,250, respectively. But 11 percent

\footnotetext{
${ }^{15} 30$ percent of men purchase the $\$ 158$ daily benefit unlimited duration policy; 5 percent of women purchase the $\$ 158$ daily benefit 3 year duration policy; 25 percent of women purchase the \$158 daily benefit unlimited duration policy and 11 percent of women purchase the $\$ 241$ daily benefit unlimited duration policy.
} 
of men, those from the $71^{\text {st }}$ to 81 st wealth percentile, and 23 percent of women, those from the $60^{\text {th }}$ to $82^{\text {nd }}$ wealth percentiles, will switch from non-partnership to partnership policies. As with induced purchasers, men prefer the \$158 dollar-for-dollar policy and women prefer the \$241 total asset protection policy. The average EPVs of Medicaid benefits of those who switch from non-partnership to partnership policies will increase from $\$ 0$ to $\$ 4,119$ for men and $\$ 3,385$ to $\$ 21,822$ for women. ${ }^{16}$ The very poor and very wealthy will not change their long-term care insurance purchase decisions. Averaged over all four groups — those who would have purchased a non-partnership policy and remain with a non-partnership after the introduction of the program, those who switch from a non-partnership to a partnership policy, those who are induced to purchase insurance, and those who remain uninsured - a one dollar savings in Medicaid costs would require \$1.68 and \$5.38 Medicaid benefits, for single males and females respectively, paid to those who would purchase non-partnership policy anyway.

\section{Conclusions}

We construct an intertemporal optimization model of the long-term care insurance purchase decision faced by single individuals. Assuming plausible preference parameters, we conclude that typical partnership programs would increase long-term care insurance coverage rates by 5 percent and 4 percent for single males and single females, respectively. A substantial part of the subsidy would go to those who would have purchased coverage anyway, and many induced purchasers are at relatively low risk of becoming Medicaid eligible. We estimate that each one-dollar saving in Medicaid costs requires partnership subsidies of \$1.68 to \$2.30 for single males and $\$ 4.10$ to $\$ 5.38$ for single females.

The finding of our simulation model that the programs are unlikely to reduce Medicaid costs, inclusive of the cost of the subsidy, is consistent with the empirical findings of Courtemanche and He (2009), Shah Goda (2011), Chan and Sun (2011), and Lin and Prince (2012). These findings are subject to two caveats. First, the Brown and Finkelstein (2008) model predicts that willingness to pay becomes positive at the $70^{\text {th }}$ percentile of the male and $60^{\text {th }}$ percentile of the female wealth distributions. If individuals were rational and well-informed, and

\footnotetext{
${ }^{16}$ Prior to the introduction of the partnership program, all men who purchase long-term care insurance opt for an unlimited duration policy. Thus, the Medicaid share of costs is zero. In contrast, women from the $60^{\text {th }}$ to the $64^{\text {th }}$ percentiles opt for a 3-year duration policy while those above the $64^{\text {th }}$ percentile opt for and an unlimited duration policy.
} 
the model captured all relevant aspects of their insurance purchase decision, we might expect to observe coverage rates of about one-third. In reality, coverage rates hover around 10 percent. It is possible that the partnership program may increase the salience of the decision to purchase long-term care insurance, leading to a greater increase in coverage than predicted by our model.

Our second caveat is that it might be possible to design a subsidy that targeted only those currently unwilling to purchase insurance. In our stylized model, this is quite straightforward. One would simply restrict the subsidy to individuals with assets below the threshold at which purchase becomes optimal. In reality, the purchase decision is influenced by unobservable factors. It would be necessary to apply restrictive conditions to exclude those who would purchase anyway, thereby substantially reducing take-up. 


\section{References}

America’s Health Insurance Plans. 2007. “Long-Term Care Insurance Partnerships: New Choices for Consumers - Potential Savings for Federal and State Government.” Available at: http://www.ahip.org/Savings-from-Expanded-Long-Term-Care-Partnerships

2012. "Who Buys Long-Term Care Insurance in 2010-2011?” Available at: http://www.ahip.org/Issues/Long-Term-Care-Insurance.aspx

Brown, Jeffrey R., and Amy Finkelstein. 2004. "The Interaction of Public and Private Insurance: Medicaid and the Long-Term Care Insurance Market.” Working Paper No. 10,989. Cambridge, MA: National Bureau of Economic Research.

Brown, Jeffrey R. and Amy Finkelstein. 2007. "Why Is the Market for Long-Term Care Insurance So Small?” Journal of Public Economics 91: 1967-1991.

2008. "The Interaction of Public and Private Insurance: Medicaid and the Long-Term Care Insurance Market.” American Economic Review 98(3): 1083-1102.

Brown, Jeffrey R., Norma B. Coe, and Amy Finkelstein. 2007. "Medicaid Crowd-Out of Private Long-Term Care Insurance Demand: Evidence from the Health and Retirement Survey.” Tax Policy and the Economy 21: 1-34.

Chan, Kwok Ho and Wei Sun. 2011. “A Dynamic Analysis of Long-Term Care Insurance Purchase Decisions.” Unpublished Working Paper.

Courtemanche, Charles and Daifeng He. 2009. "Tax Incentives and the Decision to Purchase Long-Term Care Insurance.” Journal of Public Economics 93: 296-310.

Lin, Haizhen and Jeffrey Prince. 2012. “The Impact of the Partnership Long-Term Care Insurance Program on Private Coverage and Medicaid Expenditures.” Working Paper. Bloomington, IN: Indiana University Kelley School of Business.

MetLife Mature Market Institute. 2012. Market Survey of Long-Term Care Costs. New York, NY.

National Conference of State Legislatures. 2013. “A Guide to Long-Term Care for State Policy Makers: The Long-Term Care Partnership Program.” Available at: http://www.ncsl.org/issues-research/health/archive-the-long-term-care-partnershipprogram.aspx

National Health Policy Forum. 2013. "National Spending for Long-Term Services and Supports (LTSS), 2011.” Available at: http://www.nhpf.org/library/the-basics/Basics_LTSS_0201-13.pdf 
Pauly, Mark V. 1990. “The Rational Non-Purchase of Long-Term Care Insurance.” Journal of Political Economy 98(1): 153-168.

Robinson, James. 2002. “A Long-Term Care Status Transition Model.” Unpublished paper.

Rothstein, Joanie. 2007. "Long-Term Care Partnership Expansion: A New Opportunity for States.” Issue Brief. Princeton, NJ: Robert Wood Johnson Foundation.

Shah Goda, Gopi. 2011. "Do Tax Subsidies for Private Insurance Reduce Medicaid Costs? Evidence from the Market for Long-Term Care Insurance.” Journal of Public Economics 95(7-8): 744-757.

U.S. Government Accountability Office. 2005. "Overview of the Long-Term Care Partnership Program.” Available at: http://www.gao.gov/new.items/d051021r.pdf 
Figure 1A. Willingness to Pay for Private Long-Term Care Insurance-Single Male

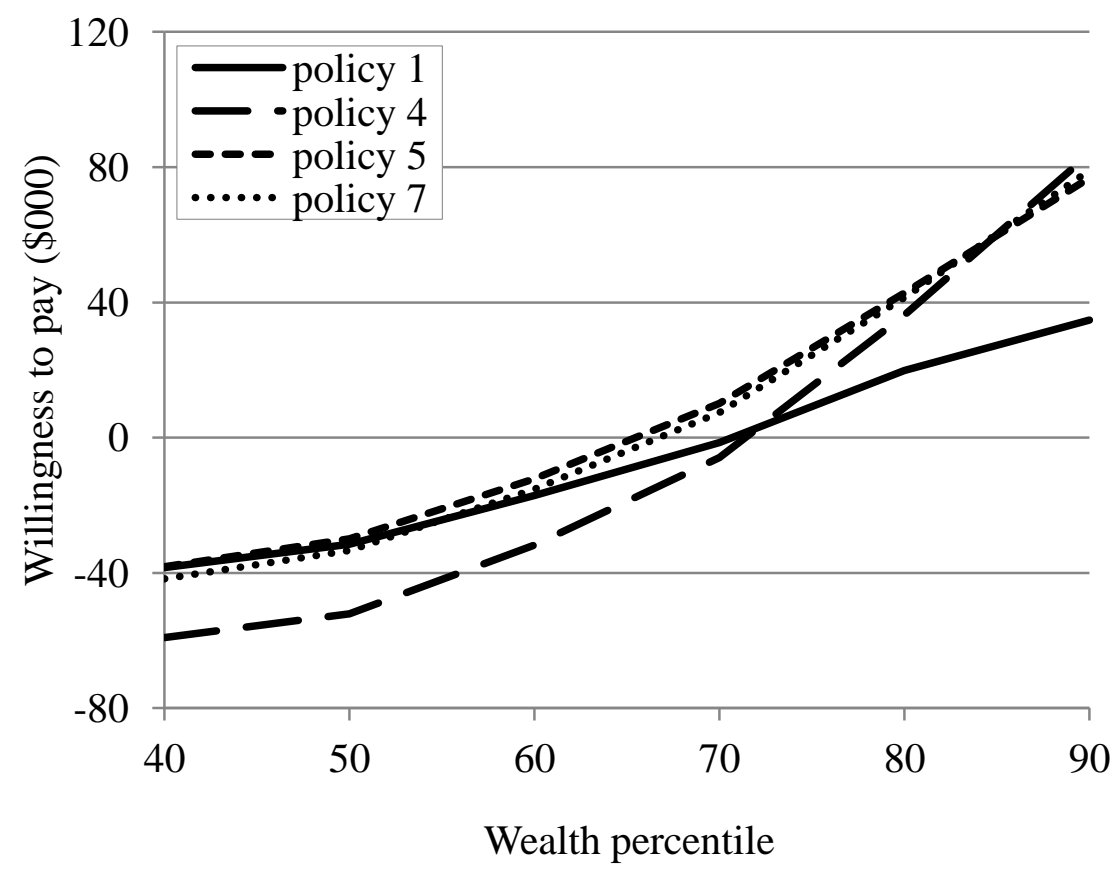

Note: Authors’ calculations.

Figure 1B. Willingness to Pay for Private Long-Term Care Insurance - Single Female

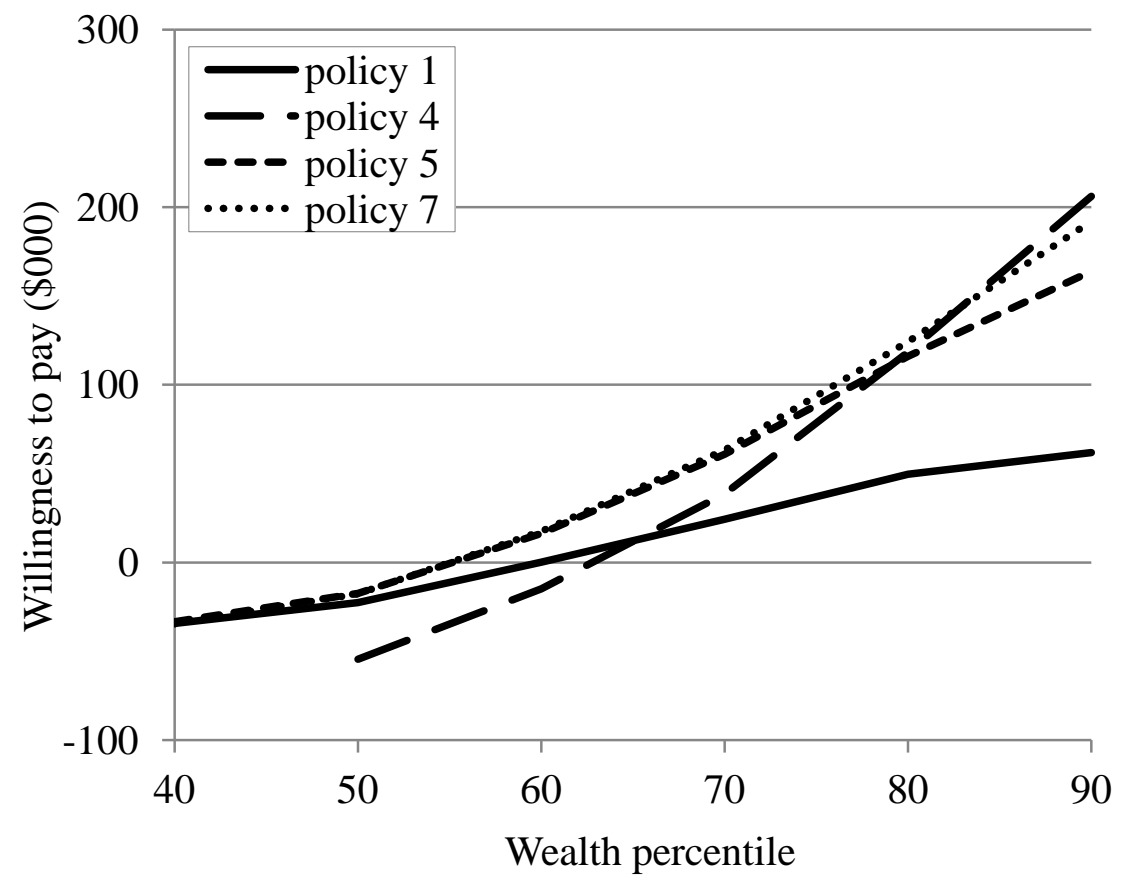

Note: Authors' calculations. 
Table 1. Medicaid Share of the EPDV of Long-Term Care Expenditure

\begin{tabular}{|c|c|c|c|c|c|c|c|c|}
\hline Wealth percentile & No private insurance & Policy 1 & Policy 2 & Policy 3 & Policy 4 & Policy 5 & Policy 6 & Policy 7 \\
\hline \multicolumn{9}{|c|}{ Men } \\
\hline 20th & 0.894 & 0.275 & 0.036 & 0.242 & 0.000 & 0.276 & 0.245 & 0.245 \\
\hline 30th & 0.823 & 0.241 & 0.017 & 0.219 & 0.000 & 0.244 & 0.229 & 0.229 \\
\hline 40th & 0.736 & 0.207 & 0.003 & 0.187 & 0.000 & 0.219 & 0.216 & 0.216 \\
\hline 50th & 0.633 & 0.177 & 0.000 & 0.140 & 0.000 & 0.206 & 0.205 & 0.205 \\
\hline 60th & 0.507 & 0.137 & 0.000 & 0.099 & 0.000 & 0.194 & 0.193 & 0.193 \\
\hline 70th & 0.365 & 0.086 & 0.000 & 0.059 & 0.000 & 0.182 & 0.188 & 0.188 \\
\hline 80th & 0.210 & 0.030 & 0.000 & 0.018 & 0.000 & 0.144 & 0.160 & 0.174 \\
\hline 90th & 0.078 & 0.003 & 0.000 & 0.002 & 0.000 & 0.078 & 0.099 & 0.161 \\
\hline \multicolumn{9}{|c|}{ Women } \\
\hline 20th & 0.935 & 0.437 & 0.037 & 0.409 & 0.000 & 0.437 & 0.412 & 0.412 \\
\hline 30th & 0.888 & 0.407 & 0.019 & 0.384 & 0.000 & 0.409 & 0.395 & 0.395 \\
\hline 40th & 0.824 & 0.374 & 0.005 & 0.345 & 0.000 & 0.386 & 0.383 & 0.383 \\
\hline 50th & 0.743 & 0.331 & 0.000 & 0.274 & 0.000 & 0.371 & 0.369 & 0.369 \\
\hline 60th & 0.630 & 0.259 & 0.000 & 0.186 & 0.000 & 0.353 & 0.352 & 0.352 \\
\hline 70th & 0.482 & 0.157 & 0.000 & 0.108 & 0.000 & 0.326 & 0.339 & 0.340 \\
\hline 80th & 0.285 & 0.038 & 0.000 & 0.027 & 0.000 & 0.233 & 0.268 & 0.314 \\
\hline 90th & 0.105 & 0.001 & 0.000 & 0.001 & 0.000 & 0.093 & 0.126 & 0.287 \\
\hline
\end{tabular}

Note: Authors' calculations. 
Table 2. Medicaid Implicit Tax on Partnership and Non-partnership Policies

\begin{tabular}{lccccccc}
\hline Wealth percentile & Policy 1 & Policy 2 & Policy 3 & Policy 4 & Policy 5 & Policy 6 & Policy 7 \\
\hline & & \multicolumn{7}{c}{ Men } & & & & \\
\hline 20th & 0.958 & 0.958 & 0.895 & 0.894 & 0.957 & 0.890 & 0.890 \\
30th & 0.900 & 0.899 & 0.829 & 0.823 & 0.897 & 0.815 & 0.815 \\
40th & 0.819 & 0.819 & 0.754 & 0.736 & 0.802 & 0.714 & 0.714 \\
50th & 0.707 & 0.707 & 0.677 & 0.633 & 0.662 & 0.587 & 0.587 \\
60th & 0.573 & 0.566 & 0.560 & 0.507 & 0.485 & 0.430 & 0.430 \\
70th & 0.431 & 0.407 & 0.420 & 0.365 & 0.283 & 0.243 & 0.243 \\
80th & 0.279 & 0.235 & 0.263 & 0.210 & 0.103 & 0.068 & 0.050 \\
90th & 0.116 & 0.087 & 0.104 & 0.078 & 0.000 & -0.030 & -0.115 \\
\hline & & & Women & & & & \\
\hline 20th & 0.981 & 0.982 & 0.932 & 0.930 & 0.981 & 0.927 & 0.927 \\
30th & 0.945 & 0.949 & 0.891 & 0.888 & 0.942 & 0.871 & 0.871 \\
40th & 0.885 & 0.895 & 0.847 & 0.824 & 0.863 & 0.781 & 0.781 \\
50th & 0.812 & 0.812 & 0.830 & 0.743 & 0.734 & 0.661 & 0.661 \\
60th & 0.730 & 0.688 & 0.785 & 0.630 & 0.545 & 0.492 & 0.492 \\
70th & 0.638 & 0.526 & 0.661 & 0.482 & 0.306 & 0.253 & 0.250 \\
80th & 0.486 & 0.311 & 0.456 & 0.285 & 0.101 & 0.030 & -0.052 \\
90th & 0.205 & 0.115 & 0.184 & 0.105 & 0.023 & -0.037 & -0.322 \\
\hline
\end{tabular}

Note: Authors' calculations. 
Table 3. Net Load on Partnership and Non-partnership Policies

\begin{tabular}{lccccccc}
\hline Wealth percentile & Policy 1 & Policy 2 & Policy 3 & Policy 4 & Policy 5 & Policy 6 & Policy 7 \\
\hline & & \multicolumn{7}{c}{ Men } & & & & \\
\hline 20th & 0.979 & 0.980 & 0.948 & 0.948 & 0.979 & 0.945 & 0.945 \\
30th & 0.950 & 0.951 & 0.914 & 0.913 & 0.948 & 0.907 & 0.907 \\
40th & 0.910 & 0.911 & 0.877 & 0.869 & 0.901 & 0.857 & 0.857 \\
50th & 0.854 & 0.854 & 0.838 & 0.818 & 0.831 & 0.794 & 0.794 \\
60th & 0.786 & 0.784 & 0.780 & 0.754 & 0.742 & 0.715 & 0.715 \\
70th & 0.716 & 0.704 & 0.710 & 0.683 & 0.641 & 0.621 & 0.621 \\
80th & 0.640 & 0.618 & 0.632 & 0.605 & 0.551 & 0.534 & 0.525 \\
90th & 0.558 & 0.543 & 0.552 & 0.539 & 0.500 & 0.485 & 0.443 \\
\hline & & & Women & & & & \\
\hline 20th & 0.980 & 1.001 & 0.928 & 0.925 & 0.980 & 0.922 & 0.922 \\
30th & 0.942 & 0.966 & 0.884 & 0.899 & 0.938 & 0.864 & 0.864 \\
40th & 0.879 & 0.908 & 0.839 & 0.831 & 0.855 & 0.768 & 0.768 \\
50th & 0.801 & 0.818 & 0.820 & 0.744 & 0.718 & 0.642 & 0.642 \\
60th & 0.715 & 0.684 & 0.772 & 0.621 & 0.519 & 0.463 & 0.463 \\
70th & 0.617 & 0.510 & 0.642 & 0.462 & 0.266 & 0.210 & 0.206 \\
80th & 0.457 & 0.278 & 0.424 & 0.249 & 0.049 & -0.026 & -0.113 \\
90th & 0.159 & 0.066 & 0.137 & 0.055 & -0.034 & -0.097 & -0.399 \\
\hline
\end{tabular}

Note: Authors’ calculations. 


\section{RECENT WORKING PAPERS FROM THE CENTER FOR RETIREMENT RESEARCH AT BOSTON COLLEGE}

SSI for Disabled Immigrants: Why Do Ethnic Networks Matter? Delia Furtado and Nikolaos Theodoropoulos, February 2013

The Use of VA Disability Benefits and Social Security Disability Insurance Among Veterans

Janet M. Wilmoth, Andrew S. London, and Colleen M. Heflin, February 2013

How Does the Composition of Disability Insurance Applicants Change Across Business Cycles?

Norma B. Coe and Matthew S. Rutledge, February 2013

The Economic Implications of the Department of Labor's 2010 Proposals for BrokerDealers

Alicia H. Munnell, Anthony Webb, and Francis M. Vitagliano, January 2013

What Is the Long-Term Impact of Zebley on Adult and Child Outcomes?

Norma B. Coe and Matthew S. Rutledge, January 2013

Sticky Ages: Why Is Age 65 Still a Retirement Peak?

Norma B. Coe, Mashfiqur Khan, and Matthew S. Rutledge, January 2013

Rethinking Optimal Wealth Accumulation and Decumulation Strategies in the Wake of the Financial Crisis

Richard W. Kopcke, Anthony Webb, and Josh Hurwitz, January 2013

Employee Mobility and Employer-Provided Retirement Plans

Gopi Shah Goda, Damon Jones, and Colleen Flaherty Manchester, November 2012

Changing Sources of Income Among the Aged Population

Barry P. Bosworth and Kathleen Burke, November 2012

Holding Out or Opting Out? Deciding Between Retirement and Disability Applications in Recessions

Matthew S. Rutledge, November 2012

Automatic Enrollment, Employee Compensation, and Retirement Security

Barbara A. Butrica and Nadia S. Karamcheva, November 2012

401(k) Participant Behavior in a Volatile Economy

Barbara A. Butrica and Karen E. Smith, November 2012

All working papers are available on the Center for Retirement Research website

(http://crr.bc.edu) and can be requested by e-mail (crr@bc.edu) or phone (617-552-1762). 